\title{
Optimization of acid assisted extraction process of foxtail millet polysaccharides and its antioxidant activity
}

\author{
Yanwen Shi, Aishi Zhu*, and Linfen Shen \\ Zhejiang University of Science and Technology, Zhejiang University of Science and Technology, China
}

Received December 20, 2019; accepted January 26, 2020

\begin{abstract}
Experiments concerning hydrochloric acid assisted extraction of polysaccharides from foxtail millet were carried out. Various combinations of extraction conditions of hydrochloric acid concentration, liquid-solid ratio, extraction time and extraction temperature were investigated using the Response Surface Methodology at three levels and four variables of Box-Behnken designs to obtain the maximum yield of polysaccharides. The experimental data were fitted to a quadratic equation using multiple regression analysis and analysed. The antioxidant activity of the obtained polysaccharides was also investigated in vitro. The optimal conditions were an acid concentration of $2.4 \mathrm{~mol} \mathrm{~L}^{-1}$, a liquid-solid ratio of 19.3:1 $\mathrm{mL} \mathrm{g}^{-1}$, an extraction time of $1.2 \mathrm{~h}$, and an extraction temperature $80.6^{\circ} \mathrm{C}$. Under these conditions, the experimental yield was $52.13 \mathrm{mg} \mathrm{g}^{-1}$, which was in close agreement with the value of $52.37 \mathrm{mg} \mathrm{g}^{-1}$ predicted by the model. The mathematical model had a high correlation with experimental data $(p<0.05)$. The polysaccharides of foxtail millet display a high radical scavenging capacity against superoxide and hydroxyl radicals.

Keywords: foxtail millet, polysaccharides, acid extraction, response surface methodology, antioxidant activity
\end{abstract}

\section{INTRODUCTION}

Millet is an important crop for fodder and human food in the semiarid tropics of Asia and Africa, especially in India, Mali, Nigeria, China, and Niger. Foxtail millet is an important crop species of millet. It is rich in calcium, dietary fibre and polyphenols, which benefit human health (Radhika, et al., 2011). The research results show that foxtail millet also contains polysaccharides (Zhu, et al., 2014).

*Corresponding author e-mail: zhuaishi86@163.com
In recent decades, numerous studies have demonstrated that polysaccharides have the therapeutic value of scavenging free radicals and few biological side effects; therefore, many researchers are paying more attention to polysaccharides as natural antioxidants (Guo et al., 2016; Wang et al., 2014a, b; Yuan et al., 2017). Response surface methodology (RSM) is widely used to optimize the extraction process variables, this is due to its efficiency at optimizing the complex processes variables (Quan et al., 2015; Osman et al., 2016; Tian et al., 2017; Zeng et al., 2015).

Almost no reports are available in the literature concerning studies to optimize the acid assisted extraction conditions of foxtail millet polysaccharides (FMP) and its antioxidant activity in vitro. The method of polysaccharide extraction using acidic aqueous solution can improve the purity, the yield and the activity of the polysaccharides extracted (Yaich et al., 2013). However, an excessively high acid concentration was not applied to improve the yield of polysaccharides, because overly acid solutions may accelerate the degradation of polysaccharides (Gan et al., 2010). Therefore, the optimization of processing conditions for the acid assisted extraction of FMP and its antioxidant activity in vitro were researched in this study. The effects of hydrochloric acid aqueous solution concentration $\left(\mathrm{mol} \mathrm{L}^{-1}\right)$, liquid-solid ratio (solution volume versus material mass, $\left.\mathrm{mL} \mathrm{g}^{-1}\right)$, extraction time $(\mathrm{h})$, and extraction temperature $\left({ }^{\circ} \mathrm{C}\right)$ on the yield of FMP were studied respectively. Then

(C) 2020 Institute of Agrophysics, Polish Academy of Sciences 
RSM was employed to optimize the acid assisted extraction conditions and to roundly evaluate the degree of influence of the extraction parameters on the yield of FMP and the interactions between them. The radical scavenging activity against superoxide and the hydroxyl radical-scavenging activity of FMP were further studied in vitro.

\section{MATERIALS AND METHODS}

The product of foxtail millet was obtained from Jilin province Yuanfang agriculture development CO., LTD, Songyuan, China, 2017 of harvest. It was first dried at $60.0^{\circ} \mathrm{C}$ in a digital constant temperature drying oven (WX881-TG, Wujiang City Prestige Electric Equipment CO., LTD, Jiangsu, China) until a constant mass was obtained, then it was ground into powder with a masher (SY-1200-1, Guangzhou City Shanyou Machinery CO., LTD, Guangzhou, China). The mashed powder was sieved with 50-mesh and then packed into plastic bags for the extraction experiments. A digital electrically heated thermostatic water bath (HH-S4, Jintan City Jinnan Instrument Manufacturing CO., LTD, Jiangsu, China) was used to control the temperature of the experiments. A rotary evaporator (YRE-201D, Gongyi City Yuhua Instrument CO., LTD, Henan, China) was applied to concentrate the filtrate. A centrifuge (TGL-16G, Changzhou Meixiang Instrument CO., LTD, Jiangsu, China) was used to centrifuge the suspension solution obtained. The concentration of polysaccharides in the extracting solution was measured with a UV-Vis spectrophotometer (T6v, Nanjing Feile Instrument CO., LTD, Jiangsu, China). All chemical reagents were analytically pure.

The foxtail millet powder dosage of each experiment was $5.0 \mathrm{~g}$. The raw material was placed into a three-neck flask $(250 \mathrm{~mL})$, and then it was extracted with hydrochloric acid solution without stirring. In the pre-experiment, it was found that the polysaccharide yield obtained from the second extraction was only approximately $1 \%$ of the first, so the extraction was carried out only once at different hydrochloric acid concentrations $(2.0,2.2,2.4,2.6$ and $2.8 \mathrm{~mol}$ $\left.\mathrm{L}^{-1}\right)$, liquid-solid ratios $(10.0,15.0,20.0,25.0$ and $30.0 \mathrm{~mL}$ $\left.\mathrm{g}^{-1}\right)$, extraction time $(0.5,1.0,1.5,2.0$ and $2.5 \mathrm{~h})$, extraction temperature $\left(50,60,70,80\right.$ and $\left.90^{\circ} \mathrm{C}\right)$, respectively. After the extraction, the mash was first cooled with cold water, and then vacuum-filtered through a Buchner funnel. The obtained filtrate was placed in a rotary evaporator, and concentrated to one-fifth of the initial volume under vacuum. Four volumes of dehydrated ethanol were added to the concentrate obtained, and mixed to form a solution, which had a final ethanol concentration of $80 \%$ in order to alcohol-precipitate the polysaccharides. The suspension solution obtained was centrifuged at 2000 r.p.m. for $10 \mathrm{~min}$, the supernatant fluid was removed and the precipitate was retained, after that the dehydrated ethanol was used to wash the precipitate three times. The precipitate was collected as product and dissolved with deionized water to reach a certain volume. Each extraction experiment was performed in triplicate.

In order to determine the best combination of extraction conditions for the yield of FMP, an experiment plan with three-levels and four-variables was designed through BoxBehnken factorial Design (BBD). In this research the four extraction variables were; hydrochloric acid concentration $\left(X_{1}\right.$, mol L $\left.{ }^{-1}\right)$, liquid-solid ratio $\left(X_{2}, \mathrm{~mL} \mathrm{~g}^{-1}\right)$, extraction time $\left(X_{3}, \mathrm{~h}\right)$, and extraction temperature $\left(X_{4},{ }^{\circ} \mathrm{C}\right)$, and the appropriate investigated range of each variable was determined by referring to the single factor pre-experimental result. The FMP yield was used as the dependent variable. The whole experiment design consisted of 29 experimental points (including five replicated experiments in the centre point) and the experiment was put into practice in a random order. The obtained experimental data were fitted with a nonlinear quadratic equation Eq. (1):

$$
Y=\beta_{0}+\sum_{i=1}^{4} \beta_{i} X_{i}+\sum_{i=1}^{4} \beta_{i} X_{i}^{2}+\sum_{i \neq j=1}^{3} \sum_{j=1}^{4} \beta_{j} X_{i} X_{j},
$$

where: $Y$ is the response value, i.e. FMP yield obtained from each extraction experiment $\left(\mathrm{mg} \mathrm{g}^{-1}\right) ; \beta_{0}, \beta_{i}, \beta_{i i}, \beta_{\mathrm{ij}}$ are constants of the regression equation, dimensionless; $X$ is the actual value of the independent variables; $X_{\mathrm{i}} X_{\mathrm{j}}$ is the interaction between independent variables; and $X_{\mathrm{i}}^{2}$ is the quadratic term of each independent variable (Lei et al., 2016; Zhu et al., 2017).

The FMP concentration was determined using the colorimetric method of phenol-sulphuric acid at $485 \mathrm{~nm}$ (Guo et al., 2016; Wang et al., 2014b). Eq. (2) below was used to calculate the yield of FMP $\left(\mathrm{mg} \mathrm{g}^{-1}\right)$ :

$$
Y=\frac{X V}{M},
$$

where: $Y$ is FMP yield $\left(\mathrm{mg} \mathrm{g}^{-1}\right) ; V$ is the metered volume of the crude FMP solution (mL); $M$ is the dosage of foxtail millet in each extraction experiment $(\mathrm{g})$; $X$ is the concentration of FMP in the extraction solution at $485 \mathrm{~nm}\left(\mathrm{mg} \mathrm{mL}^{-1}\right)$.

The scavenging of superoxide by antioxidants was estimated by the inhibition of pyrogallol acid as described previously (Wang et al., 2014a). In brief, $4.5 \mathrm{~mL}$ of 50 $\mathrm{mM}$ Tris- $\mathrm{HCl}$ buffer (pH 8.2) was mixed with $4.2 \mathrm{~mL}$ of deionized water. After incubation at $25^{\circ} \mathrm{C}$ for $20 \mathrm{~min}$, $1 \mathrm{~mL}$ of FMP solution $\left(0.2-1.0 \mathrm{mg} \mathrm{mL}^{-1}\right)$ and $0.4 \mathrm{~mL}$ of pyrogallic acid were added to the mixture. The resulting mixture was rapidly shaken and incubated at $25^{\circ} \mathrm{C}$ for $5 \mathrm{~min}$. Subsequently, $8 \mathrm{mM}$ of $\mathrm{HCl}$ was added to the mixture to terminate the reaction, and its absorbance was measured at wavelength $320 \mathrm{~nm}$. Ascorbic acid was used as a positive control. The ability of FMP to scavenge superoxide radicals was calculated using the following formula: 


$$
\text { scavenging activity }(\%)=\left(1-\frac{A_{1}}{A_{0}}\right) 100 \text {, }
$$

where: $A_{0}$ is the absorbance of the blank and $A_{1}$ is the absorbance of FMP/Vc.

Hydroxyl radical scavenging activity was measured according to the procedures of Li et al. (2014). The reaction mixture $(2.5 \mathrm{~mL})$ contained $0.5 \mathrm{~mL}$ of $\mathrm{FeSO}_{4}(1.5 \mathrm{mM})$, $0.35 \mathrm{~mL}$ of $\mathrm{H}_{2} \mathrm{O}_{2}(6.0 \mathrm{mM}), 0.15 \mathrm{~mL}$ of sodium salicylate $(20.0 \mathrm{mM})$, and $1.0 \mathrm{~mL}$ of different concentrations (0.2-1.0 mg mL $\left.\mathrm{mb}^{-1}\right)$ of polysaccharides. Ascorbic acid was used as the positive control. After incubation for $60 \mathrm{~min}$ at $37^{\circ} \mathrm{C}$, the absorbance of the hydroxylated salicylate complex formed was measured at a wavelength of $562 \mathrm{~nm}$. The percentage scavenging effect was calculated according to Eq. (4) below:

$$
\text { hydroxyl radical-scavenging activity }(\%)=\left(1-\frac{A_{1}-A_{0}}{A_{2}}\right) 100 \text {, }
$$

where: $A_{0}$ is the absorbance of the reagent blank without sodium salicylate, $A_{1}$ is the absorbance of the sample or ascorbic acid and $A_{2}$ is the absorbance of the solvent control.

Multiple non-linear regressions of the experimental data obtained were carried out using Design Expert Software. The coefficient of determination $\mathrm{R}^{2}$ was used to express the quality of the fit of the polynomial model, and the significance of the regression coefficient was checked by the $F$-test and p-value. The significant difference was denoted by $\mathrm{p}<0.05$.

\section{RESULTS AND DISCUSSION}

In order to confirm the centre value of each independent variable in the response surface experiment, the pre-experiment of the single factor experiment was implemented before the optimization experiment. The hydrochloric acid concentrations were $2.0,2.2,2.4,2.6$ and $2.8 \mathrm{~mol} \mathrm{~L}^{-1}$, the liquid-solid ratios were $10,15,20,25$ and $30 \mathrm{~mL} \mathrm{~g}^{-1}$, the extraction times were $0.5,1.0,1.5,2.0$ and $2.5 \mathrm{~h}$, the extraction temperatures were $50,60,70,80$ and $90^{\circ} \mathrm{C}$. The single factor experimental result showed that the FMP yield reached a maximum value at $2.4 \mathrm{~mol} \mathrm{~L}^{-1}$ hydrochloric acid concentration, $20: 1 \mathrm{~mL} \mathrm{~g}^{-1}$ liquid-solid ratio, $1.0 \mathrm{~h}$ extraction time, $80^{\circ} \mathrm{C}$ extraction temperature, respectively. Thus the range of 2.2-2.6 mol L-1 of hydrochloric acid concentration, 15.0$25.0 \mathrm{~mL} \mathrm{~g}^{-1}$ of liquid-solid ratio, $0.5-1.5 \mathrm{~h}$ of extraction time and an extraction temperature of $70-90^{\circ} \mathrm{C}$ (Table 1) were the conditions adopted in the RSM experiment.

The investigated factors and their levels, the experiment design plan and the result of each experiment are listed in Table 1. The response values of the FMP yield obtained from the research and the actual values of the parameters were fit to a second order polynomial equation (Eq. (5)), and a regression analysis was carried out. All of the analysis results are summarized in Table 2:

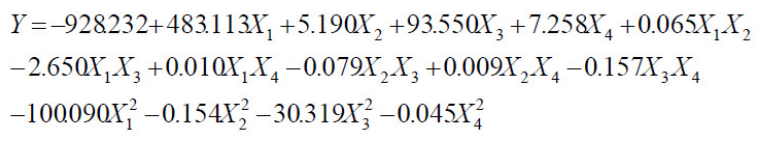

when the value of probability (p) of some item is less than 0.05 , this item has a significant effect on the FMP yield within the range of the investigation. The analysis of variance demonstrates that the regression equation obtained has a high significance level $(\mathrm{p}<0.0001)$ with an $F$ value of 36.43 , and its suitability for use as experimental data is further evidenced by the values of the determination coefficient $R^{2}$ and the adjus ted $R^{2}$, which are 0.9733 and 0.9466 respectively. In order to examine the adequacy of the fitting model and confirm whether it would lead to bad or misleading results, a residual analysis was carried out. The residual and the effect diagrams of the experimental data are shown in Fig. 1 (Maran et al., 2013). As seen in Fig. 1a, the predicted values of the model are fairly close to the actual values of the experiments, all of the experimental and predicted points are near the $45^{\circ}$ line, and this suggests that the regression equation obtained could successfully reveal the relationship between the variables and the dependent variables of the process. The normal \% probability chart of residuals for dependent variables shown in Fig. 1b is normally distributed, because all of the points lie closely on a straight line and show no variance deviation. The degree of fit of the regression equation was analysed by drawing a diagram of the relationship between the internally studentized residuals and the predicted values, the results show that all of the points are located within the limit values (Fig. 1c). Since all of the leverage values are below 1 (Fig. 1d), there are no outliers or unexpected errors in the regression equation. At the same time, the difference in the beta values plot in Fig. 1e shows no excessive influence of observation on the regression coefficients. Fig. If shows that the Cook's distance values are located within the determined range, this reveals that there are no impact observations in the experimental data. Hence, no obvious patterns are found in the analysis of the regression equation and manifested in the accuracy of the obtained pattern. The results of the variance and residual analysis certify a good consistency of the data from the BBD experiment, and the FMP yield could be accurately predicted using the regression equation obtained. The p-value $(<0.0001)$ of the model is less than 0.01 , indicating that the regression equation (Eq. (5)) could give a better fit to the experimental data. The linear term of $X_{3}$ and each quadratic term $(p<0.01)$ also show an extremely significant effect on the yield of FMP. The linear term of $X_{2}$ and $X_{4}(\mathrm{p}<0.05)$ are significant. The linear term of $X_{1}$ and six interactive terms are nevertheless not significant $(\mathrm{p}>0.05)$.

The relationship between the responses and the experimental variables may be illustrated graphically using three-dimensional (3D) response surface plots (Fig. 2) to 
Table 1. Experimental design and results of alkali extraction

\begin{tabular}{|c|c|c|c|c|c|}
\hline \multirow{2}{*}{$\begin{array}{c}\text { Test } \\
\text { number }\end{array}$} & $\begin{array}{c}\text { Acid } \\
\text { concentration }\end{array}$ & $\begin{array}{l}\text { Liquid-solid } \\
\text { ratio }\end{array}$ & $\begin{array}{l}\text { Extraction } \\
\text { time }\end{array}$ & $\begin{array}{l}\text { Extraction } \\
\text { temperature }\end{array}$ & \multirow{2}{*}{$\begin{array}{c}Y \\
\left(\mathrm{mg} \mathrm{g}^{-1}\right)\end{array}$} \\
\hline & $X_{1}\left(\mathrm{~mol} \mathrm{~L}^{-1}\right)$ & $X_{2}\left(\mathrm{~mL} \mathrm{~g}^{-1}\right)$ & $X_{3}(\mathrm{~h})$ & $X_{4}\left({ }^{\circ} \mathrm{C}\right)$ & \\
\hline 1 & 2.2 & 15.0 & 1.0 & 80 & 45.07 \\
\hline 2 & 2.6 & 15.0 & 1.0 & 80 & 45.38 \\
\hline 3 & 2.2 & 25.0 & 1.0 & 80 & 43.03 \\
\hline 4 & 2.6 & 25.0 & 1.0 & 80 & 43.60 \\
\hline 5 & 2.4 & 20.0 & 0.5 & 70 & 32.71 \\
\hline 6 & 2.4 & 20.0 & 1.5 & 70 & 45.78 \\
\hline 7 & 2.4 & 20.0 & 0.5 & 90 & 35.86 \\
\hline 8 & 2.4 & 20.0 & 1.5 & 90 & 45.79 \\
\hline 9 & 2.2 & 20.0 & 1.0 & 70 & 39.59 \\
\hline 10 & 2.6 & 20.0 & 1.0 & 70 & 40.31 \\
\hline 11 & 2.2 & 20.0 & 1.0 & 90 & 42.46 \\
\hline 12 & 2.6 & 20.0 & 1.0 & 90 & 43.26 \\
\hline 13 & 2.4 & 15.0 & 0.5 & 80 & 33.40 \\
\hline 14 & 2.4 & 25.0 & 0.5 & 80 & 31.60 \\
\hline 15 & 2.4 & 15.0 & 1.5 & 80 & 45.77 \\
\hline 16 & 2.4 & 25.0 & 1.5 & 80 & 43.18 \\
\hline 17 & 2.2 & 20.0 & 0.5 & 80 & 31.56 \\
\hline 18 & 2.6 & 20.0 & 0.5 & 80 & 33.45 \\
\hline 19 & 2.2 & 20.0 & 1.5 & 80 & 45.85 \\
\hline 20 & 2.6 & 20.0 & 1.5 & 80 & 46.68 \\
\hline 21 & 2.4 & 15.0 & 1.0 & 70 & 43.45 \\
\hline 22 & 2.4 & 25.0 & 1.0 & 70 & 40.69 \\
\hline 23 & 2.4 & 15.0 & 1.0 & 90 & 43.71 \\
\hline 24 & 2.4 & 25.0 & 1.0 & 90 & 42.65 \\
\hline 25 & 2.4 & 20.0 & 1.0 & 80 & 50.20 \\
\hline 26 & 2.4 & 20.0 & 1.0 & 80 & 51.74 \\
\hline 27 & 2.4 & 20.0 & 1.0 & 80 & 51.79 \\
\hline 28 & 2.4 & 20.0 & 1.0 & 80 & 50.38 \\
\hline 29 & 2.4 & 20.0 & 1.0 & 80 & 50.88 \\
\hline
\end{tabular}

investigate the interactions of the variables. Each plot showed a pair of factors by keeping the other factors constant at its middle level.

The 3D response surface plot for extraction yield as a function of acid concentration and liquid-solid ratio at a fixed extraction time $(1.0 \mathrm{~h})$ and extraction temperature $\left(80^{\circ} \mathrm{C}\right)$ is given in Fig. $2 \mathrm{a}$. It may be seen that the contributions of acid concentration and liquid-solid ratio to the tendency and strength of the effect on the yield are similar, there is an increase followed by a decrease in yield with an increase in acid concentration and liquid-solid ratio. Acid can help to weaken the chemical and physical effect between the polymer molecules of the cell wall causing more polysaccharides to dissolve from the cells into solution, for this reason the FMP yield is increased, whereas an excessively high acid concentration would bring about a reduction in the FMP yield as a result of polysaccharide structure breakdown caused by acid catalysed hydrolysis (Bendahou et al., 2007). The extraction yield increased at first with the increase in the liquid-solid ratio due to the driving force rising for the mass transfer with the augmentation of the liquid-solid ratio (Guo et al., 2016). However, the yield clearly decreases with the continuously increasing ratio, because of the acid-catalysed hydrolysis. These results are similar to those of earlier observations (Guo et al., 2016; Wang et al., 2014b; Yuan et al., 2017; Zeng et al., 2015). Fig. 2b shows the 3D response of the surface plot with varying acid concentration and extraction time under a liquid-solid ratio of $20.0 \mathrm{~mL} \mathrm{~g}^{-1}$, and an extraction temperature of $80^{\circ} \mathrm{C}$. It demonstrates that the extraction time 
Table 2. Analysis of variance for regression equation to alkali extraction

\begin{tabular}{|c|c|c|c|c|c|c|}
\hline Source & Sum of squares & $\mathrm{df}$ & Mean square & F value & Prob $>F$ & Significance \\
\hline Model & 975.15 & 14 & 69.65 & 36.43 & $<0.0001$ & $\ddagger$ \\
\hline$X_{1}$ & 2.18 & 1 & 2.18 & 1.14 & 0.3032 & $*$ \\
\hline$X_{2}$ & 12.06 & 1 & 12.06 & 6.31 & 0.0249 & $\dagger$ \\
\hline$X_{3}$ & 462.15 & 1 & 462.15 & 241.74 & $<0.0001$ & 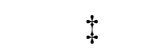 \\
\hline$X_{4}$ & 10.45 & 1 & 10.45 & 5.47 & 0.0347 & $\dagger$ \\
\hline$X_{1} X_{2}$ & 0.017 & 1 & 0.017 & $8.840 \times 10^{-3}$ & 0.9264 & $*$ \\
\hline$X_{1} X_{3}$ & 0.28 & 1 & 0.28 & 0.15 & 0.7072 & $*$ \\
\hline$X_{1} X_{4}$ & $1.600 \times 10^{-3}$ & 1 & $1.600 \times 10^{-3}$ & $8.369 \times 10^{-3}$ & 0.9773 & $*$ \\
\hline$X_{2} X_{3}$ & 0.16 & 1 & 0.16 & 0.082 & 0.7793 & * \\
\hline$X_{2} X_{4}$ & 0.72 & 1 & 0.72 & 0.38 & 0.5486 & $*$ \\
\hline$X_{3} X_{4}$ & 2.46 & 1 & 2.46 & 1.29 & 0.2752 & * \\
\hline$X_{1}^{2}$ & 103.97 & 1 & 103.97 & 54.38 & $<0.0001$ & $\ddagger$ \\
\hline$X_{2}^{2}$ & 95.76 & 1 & 95.76 & 50.09 & $<0.0001$ & $\ddagger$ \\
\hline$X_{3}^{2}$ & 372.67 & 1 & 372.67 & 194.94 & $<0.0001$ & $t$ \\
\hline$X_{4}^{2}$ & 131.41 & 1 & 131.41 & 68.74 & $<0.0001$ & $\ddagger$ \\
\hline Residual & 26.76 & 14 & 1.91 & & & \\
\hline Lack of fit & 24.55 & 10 & 2.46 & 4.44 & 0.0818 & $*$ \\
\hline Pure error & 2.21 & 4 & 0.55 & & & \\
\hline \multirow[t]{2}{*}{ Cor total } & 1001.91 & 28 & & & & \\
\hline & & $\mathrm{R}^{2}=0.9733$ & & Adj. $\mathrm{R}^{2}=0.9466$ & & \\
\hline
\end{tabular}

$*$ Not significant, $\uparrow$ significant, $\ddagger$ extremely significant, $\mathrm{df}$ - degrees of freedom.

has a similar effect on yield as the liquid-solid ratio, but the influence of the extraction time is greater than that of the acid concentration. This is possible, because the process of breaking the foxtail millet cell wall and the penetration of liquid into the dried powdered foxtail millet causing the dissolution of the polysaccharides, which subsequently diffuse out from the material to the exterior solvent, requires a certain time (Guo et al., 2016). However, the FMP yield is reduced with increasing extraction time. It is supposed that polysaccharides dissolved in acid solution were hydrolysed because of their long period of time in solution (Chen et al., 2007). This result is in agreement with the observations of Wang et al. (2014b), Yuan et al. (2017), and Guo et al. (2016). The 3D response surface plot for the extraction yield as a function of acid concentration and extraction temperature at a fixed liquid-solid ratio $\left(20.0 \mathrm{~mL} \mathrm{~g}^{-1}\right)$ and extraction time $(1.0 \mathrm{~h})$ is given in Fig. 2c. From Fig. 2c we may observe that the extraction yield is increased first with the increase in the extraction temperature, and then the extraction yield is decreased after the peak. With the increase in temperature, the solvent viscosity is decreased to improve the solvent and solute diffusivity in the suspension solution system, which improves the solubility capacity of the polysaccharides (Wang et al., 2014b). However, a high temperature would cause the yield to decrease due to the degradation of polysaccharides at a high temperature (Ren et al., 2008). This result is consistent with the studies concerning polysaccharides from Monascus mycelium by Wang et al. (2014b) and the polysaccharides from Huaguoshan Yunwu tea by Yuan et al. (2017). The 3D response surface plot at varying liquid-solid ratios and extraction times in a fixed acid concentration of $2.4 \mathrm{~mol}$ $\mathrm{L}^{-1}$, extraction temperature $80^{\circ} \mathrm{C}$; the liquid-solid ratio and extraction temperature were fixed at an acid concentration of $2.4 \mathrm{~mol} \mathrm{~L}^{-1}$, extraction time $1.0 \mathrm{~h}$; extraction time and extraction temperature at a fixed acid concentration of 2.4 mol L-1 and a liquid-solid ratio of $20.0 \mathrm{~mL} \mathrm{~g}^{-1}$ is given in Fig. 2d, Fig. 2e and Fig. 2f, respectively. Fig. 2d shows the changed trend of the yield with increases in extraction time and liquid-solid ratio. Fig. 2e shows the changed trend of the yield with increases in extraction temperature and liquid-solid ratio, and Fig. $2 \mathrm{f}$ shows the changed trend of yield with increases in extraction time and extraction temperature. Their changed trends are similar, i.e. at first the yield is increased and then decreased with the increase in each factor, moreover the influence of extraction time is similarly greater than the liquid-solid ratio or extraction temperature.

It may be determined from Eq. (5) that the best extraction conditions of FMP are $2.41 \mathrm{~mol} \mathrm{~L}^{-1}$ of acid concentration, 19.31:1 $\mathrm{mL} \mathrm{g}^{-1}$ of liquid-solid ratio, $1.20 \mathrm{~h}$ extraction time, $80.62^{\circ} \mathrm{C}$ extraction temperature, and the highest FMP yield as predicted by Eq. (5) is $52.37 \mathrm{mg} \mathrm{g}^{-1}$ for this combination of conditions. 

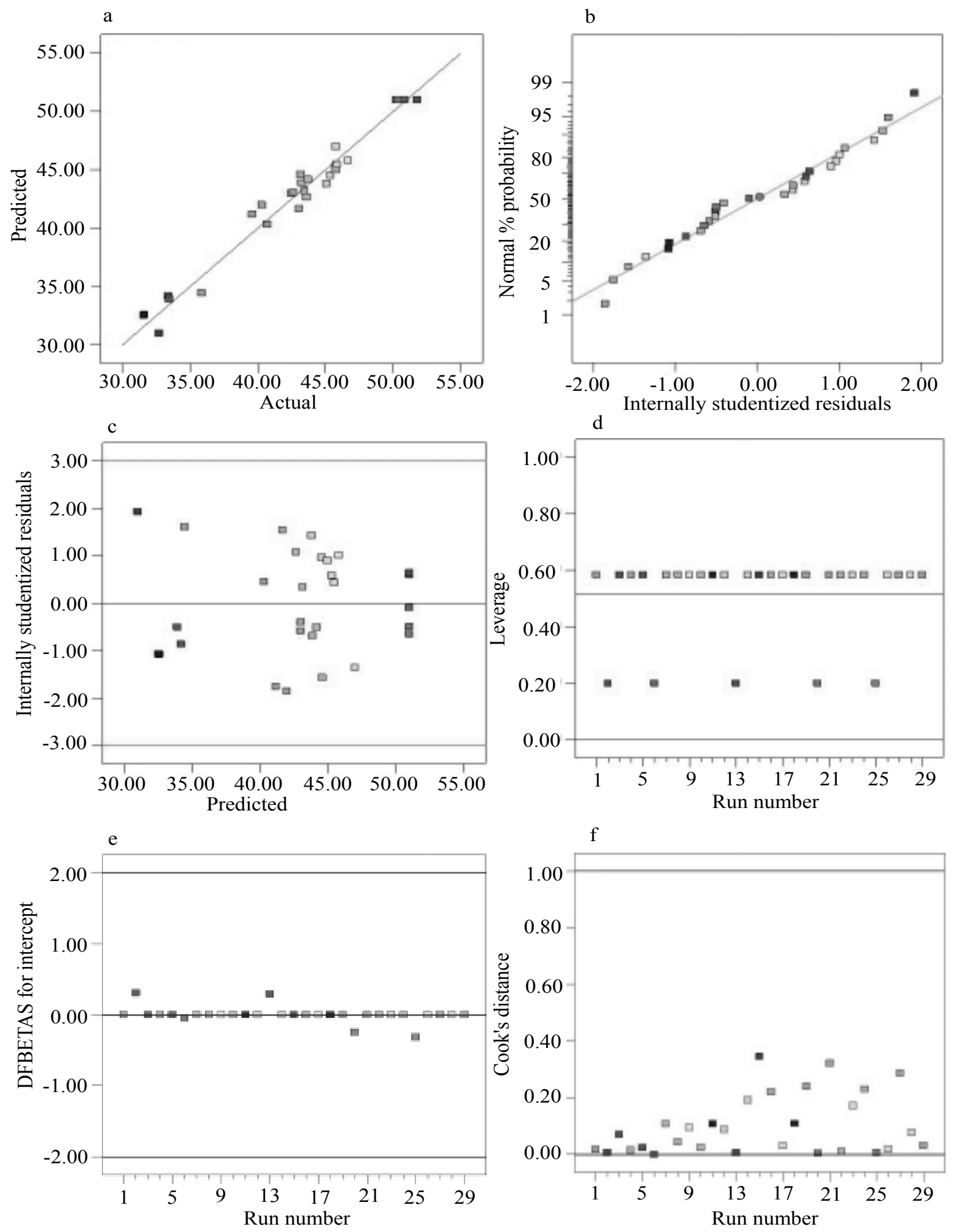

Fig. 1. Diagnostic plots for the model adequacy of acid extraction. 


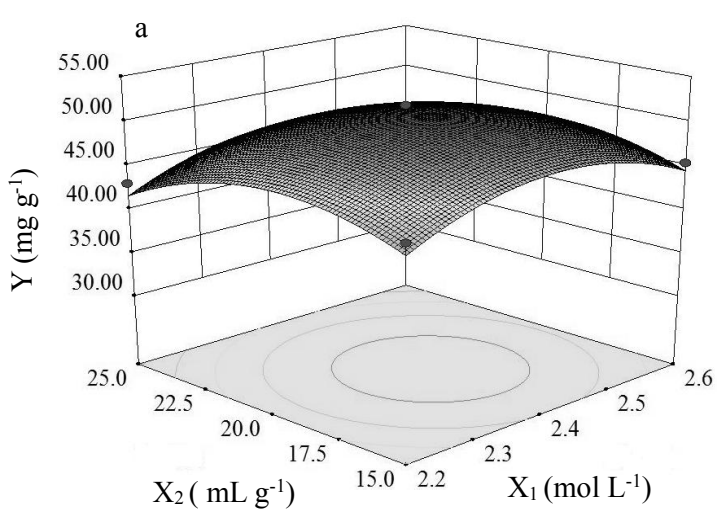

a. Response surface plot of $Y=\mathrm{f}\left(X_{1}, X_{2}\right)$

$\left(\mathrm{X}_{3}=1.0 \mathrm{~h}, \mathrm{X}_{4}=80.0^{\circ} \mathrm{C}\right)$

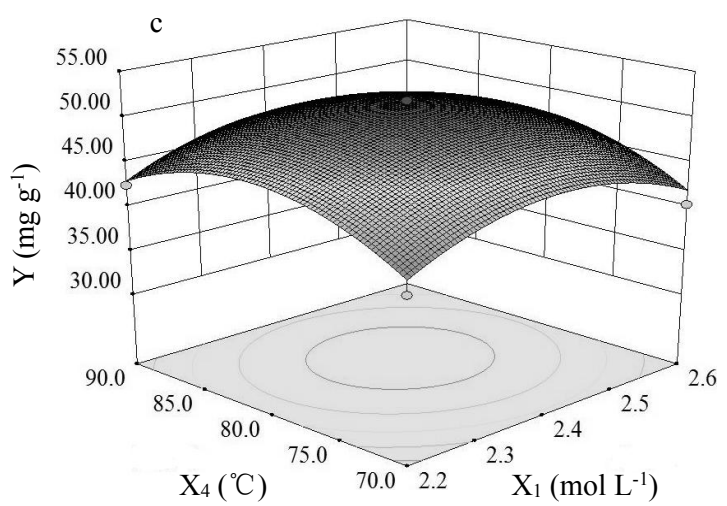

c. Response surface plot of $Y=\mathrm{f}\left(X_{1}, X_{4}\right)$

$\left(\mathrm{X}_{2}=20.0 \mathrm{~mL} \mathrm{~g}^{-1}, \mathrm{X}_{3}=1.0 \mathrm{~h}\right)$

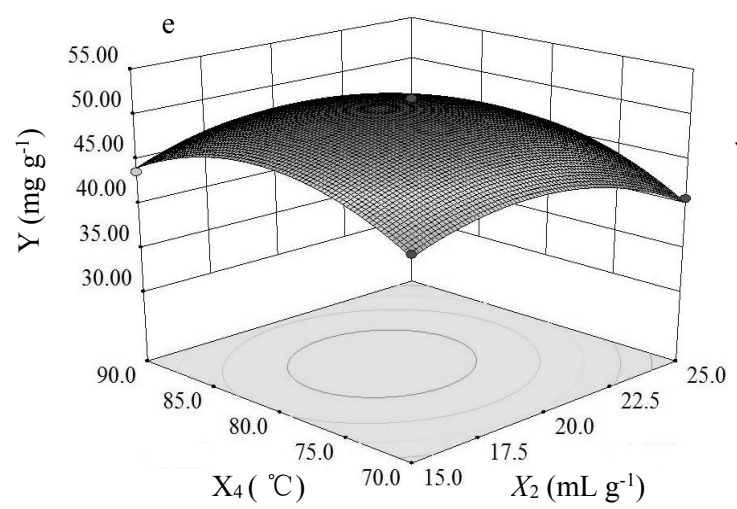

e. Response surface plot of $Y=\mathrm{f}\left(X_{2}, X_{4}\right)$

$\left(\mathrm{X}_{1}=2.4 \mathrm{~mol} \mathrm{~L}^{-1}, \mathrm{X}_{3}=1.0 \mathrm{~h}\right)$

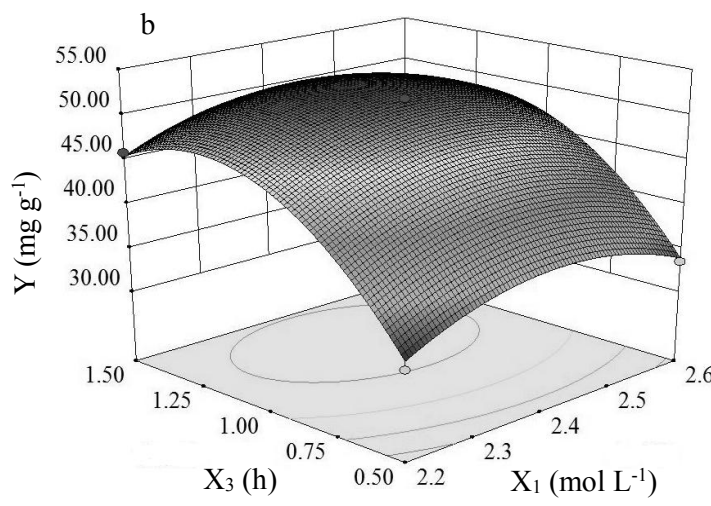

b. Response surface plot of $Y=\mathrm{f}\left(X_{1}, X_{3}\right)$

$\left(\mathrm{X}_{2}=20.0 \mathrm{~mL} \mathrm{~g}^{-1}, \mathrm{X}_{4}=80.0{ }^{\circ} \mathrm{C}\right)$

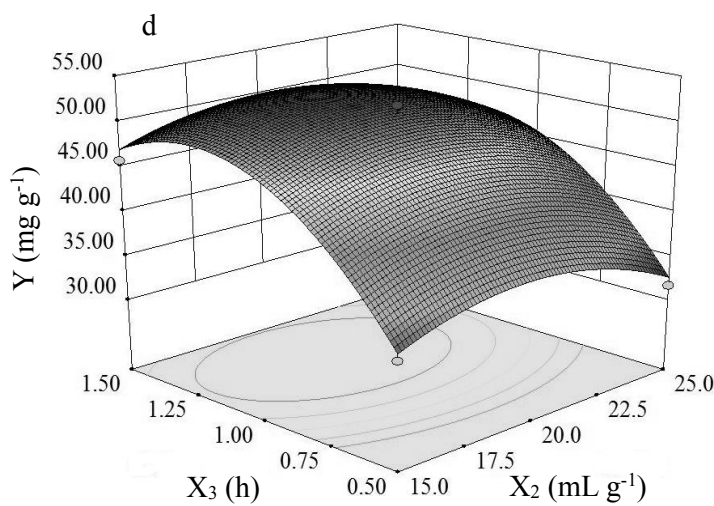

d. Response surface plot of $Y=\mathrm{f}\left(X_{2}, X_{3}\right)$

$\left(\mathrm{X}_{1}=2.4 \mathrm{~mol} \mathrm{~L}^{-1}, \mathrm{X}_{4}=80.0{ }^{\circ} \mathrm{C}\right)$

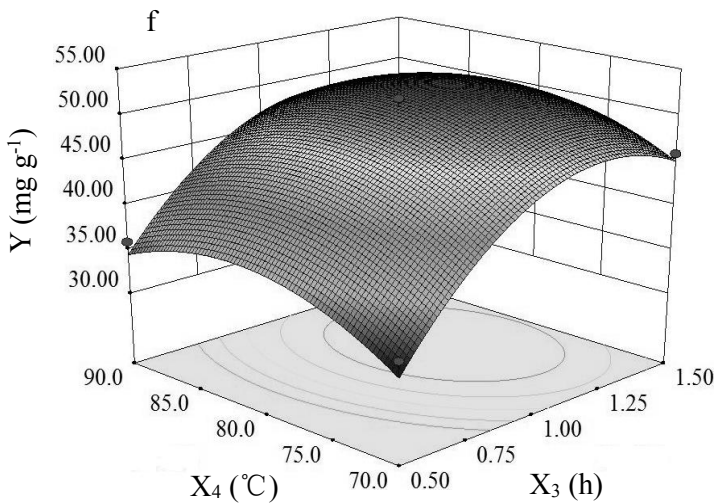

f. Response surface plot of $Y=\mathrm{f}\left(X_{3}, X_{4}\right)$

$\left(\mathrm{X}_{1}=2.4 \mathrm{~mol} \mathrm{~L}^{-1}, \mathrm{X}_{2}=20.0 \mathrm{~mL} \mathrm{~g}^{-1}\right)$

Fig. 2. Response surface plots of the effects of different combinations of conditions on polysaccharides yield. 
a

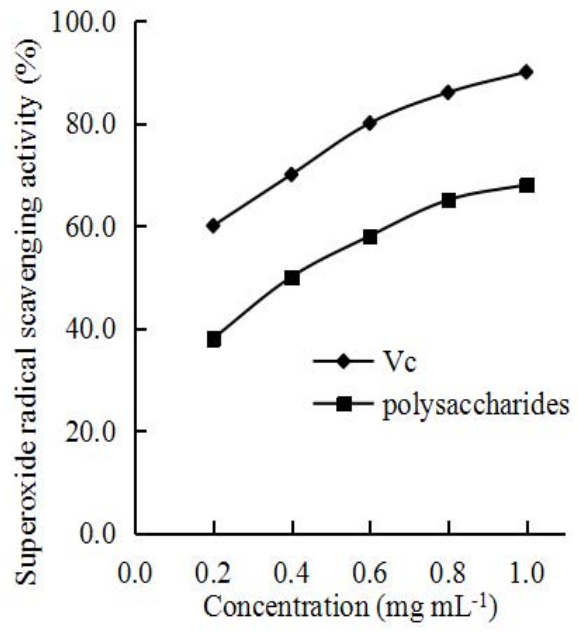

b

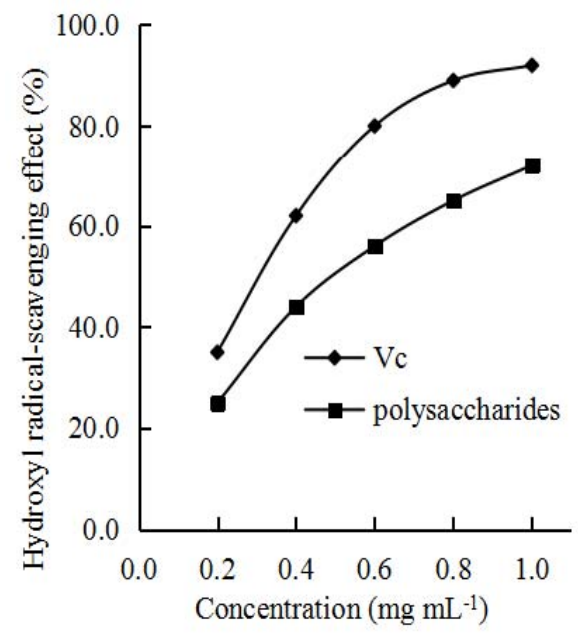

Fig. 3. Radical-scavenging activities (\%) of the polysaccharides and ascorbic acid on (a) superoxide anion and (b) hydroxyl.

The parallel tests were implemented three times to determine the accuracy of the prediction of Eq. (5) at an acid concentration of $2.4 \mathrm{~mol} \mathrm{~L}^{-1}$, a liquid-solid ratio of 19.3:1 $\mathrm{mL} \mathrm{g}^{-1}$, an extraction time of $1.2 \mathrm{~h}$, and an extraction temperature of $80.6^{\circ} \mathrm{C}$. The average experimental value of the FMP yield was $52.13 \pm 0.73 \mathrm{mg} \mathrm{g}^{-1}(\mathrm{n}=3)$, which is lower by $0.46 \%$ as compared with the value of $52.37 \mathrm{mg} \mathrm{g}^{-1}$ predicted by Eq. (5). This result could ultimately prove that the mathematical model obtained could be adequately used to predict optimization, and that the accuracy of Eq. (5) is satisfactory.

The superoxide radical, one of the precursors of singlet oxygen and hydroxyl radicals, indirectly initiates lipid peroxidation. The presence of superoxide anions can also aggravate cellular damage because of their ability to produce other kinds of free radicals and oxidizing agents (Wang et al., 2014a). The scavenging activities of FMP on superoxide anion are presented in Fig. 3a. It is obvious that the scavenging ability of FMP on superoxide radicals correlated positively with increasing concentrations in the range of the investigated concentration, however, this increase became less obvious when the concentration approached $1.0 \mathrm{mg} \mathrm{mL}^{-1}$. The results demonstrated that FMP had a noticeable effect on inhibiting the formation of superoxide radicals especially at high concentrations, although the superoxide radical scavenging rate of FMP was lower than that of ascorbic acid. Similar results have been reported for other plant polysaccharides (Wang et al., 2014a; Zhao et al., 2013).

It is important to remove hydroxyl radicals through antioxidant defence because hydroxyl radicals are one of the reactive oxygen species generated in the body, which can easily cross cell membranes, rapidly react with most biomolecules, and inflict tissue damage or cell death ( $\mathrm{Li}$ et al., 2014; Zhao et al., 2013). As shown in Fig. 3b, FMP exhibited a concentration-dependent hydroxyl radical scavenging activity in the range of the investigated concentration. The results indicated that FMP had a high level of hydroxyl radical scavenging effect, but the scavenging ability of FMP on hydroxyl radicals is lower than that of the ascorbic acid. The results were generally in agreement with some of the literature concerning the study of various polysaccharides antioxidant activities (Zhang et al., 2014; Zhao et al., 2013).

\section{CONCLUSIONS}

1. The research found that the liquid-solid ratio, extraction time and extraction temperature had a significant effect on the extraction yield of foxtail millet polysaccharides through the analysis of response surface methodology.

2 . The obtained quadratic equation had a high correlation with the experimental data, and could be effectively used to optimize the extraction process of foxtail millet polysaccharides. It was found that the optimal extraction conditions were a combination of $2.4 \mathrm{~mol} \mathrm{~L}^{-1}$ acid concentration, $19.3: 1 \mathrm{~mL} \mathrm{~g}^{-1}$ liquid-solid ratio, $1.2 \mathrm{~h}$ extraction time and $80.6^{\circ} \mathrm{C}$ extraction temperature. At the optimal combination of conditions, the foxtail millet polysaccharides yield was predicted through the use of a mathematical model to be $52.37 \mathrm{mg} \mathrm{g}^{-1}$, and the real yield obtained from experiment was $52.13 \mathrm{mg} \mathrm{g}^{-1}$ under the same optimal conditions, both the predicted and the experimental yield values were essentially in agreement.

3. The polysaccharides were found to have significant superoxide and hydroxyl radical-scavenging activity.

Conflict of interests: The authors declare that they have no conflict of interest. 


\section{REFERENCES}

Bendahou A., Dufresne A., Kaddami H., and Habibi Y., 2007. Isolation and structural characterization of hemicelluloses from palm of phoenix Dactylifera L. Carbohydrate Polymers, 68(3): 601-608. https://doi.org/10.1016/j.carbpol.2006.10.016

Chen Y., Xie M.Y., and Gong X.F., 2007. Microwave-assisted extraction used for the isolation of total triterpenoid saponins from Ganoderma atrum. J. Food Eng., 81(1), 162-170. https://doi.org/10.1016/j.jfoodeng.2006.10.018

Gan C.Y., Abdul Manaf N., and Latiff A.A., 2010. Optimization of alcohol insoluble polysaccharides (AIPS) Extraction from the parkia speciosa pod using response surface methodology (RSM). Carbohydrate Polymers, 79(4): 825-831. https://doi.org/10.1016/j.carbpol.2009.10.006

Guo L., Guo J.C., Zhu W.C., and Jiang X.R., 2016. Optimized synchronous extraction process of tea polyphenols and polysaccharides from huaguoshan yunwu tea and their antioxidant activities. Food Bioproducts Processing, 100: 303-310. https://doi.org/10.1016/j.fbp.2016.08.001

Lei Z.T., Chen H., Huang D., Zhai Y.L., and Shu G.W., 2016. Optimization of medium compositions for saccharomyces boulardii by box-behnken design. Scientific Study Res. Chemistry Chemical Eng., Biotechnol., Food Industry, 17(4): 405-416.

Li S.H., Wang L.B., Song C.F., Hu X.S., Sun H.Y., Yang Y.N., Lei Z.F., and Zhang Z.Y., 2014. Utilization of soybean curd residue for polysaccharides by Wolfiporia extensa (Peck) Ginns and the antioxidant activities in vitro. J. Taiwan Institute of Chemical Engineers, 45: 6-11. https://doi.org/10.1016/j.jtice.2013.05.019

Maran J.P., Manikandan S., Thirugnanasambandham K., Nivetha C.V., and Dinesh R., 2013. Box-behnken design based statistical modeling for ultrasound-assisted extraction of corn silk polysaccharide. Carbohydrate Polymers, 92(1): 604-611.

https://doi.org/10.1016/j.carbpol.2012.09.020

Osman H., Shigidi I., and Elkhaleefa A., 2016. Optimization of sesame seeds oil extraction operating conditions using the response surface design methodology. Scientific Study Research Chemistry Chemical Eng., Biotechnol., Food Industry, 17(4): 335-347. https://doi.org/10.4236/aces.2015.53031

Quan Y., Yang S., Wan J., Su T.T., Zhang J., and Wang Z.Y., 2015. Optimization for the extraction of polysaccharides from nostoc commune and its antioxidant and antibacterial activities. J. Taiwan Institute of Chemical Engineers, 52: 14-21. https://doi.org/10.1016/j.jtice.2015.02.004

Radhika G.B., Satyanarayana S.V., and Rao D.G., 2011. Mathematical model on thin layer drying of finger millet (Eluesine coracana). Advance J. Food Sci. Technol., 3(2): 127-131.
Ren C.J., Gao L., Wang C.M., Wu M.C., and Chen J.F., 2008. Optimization of extracting technology of hydrosoluble polysaccharides from peanut meal by alkali. Trans. CSAE, 24(7): 251-254.

Tian S.Y., Hao C.C., Xu G.K., Yang J.J., and Sun R.G., 2017. Optimization conditions for extracting polysaccharide from angelica sinensis and its antioxidant activities. J. Food Drug Analysis, 25(4): 766-775. https://doi.org/10.1016/j.jfda.2016.08.012

Wang C.Y., Wang Y., Zhang J., and Wang Z.Y., 2014a. Optimization for the extraction of polysaccharides from Gentiana scabra Bunge and their antioxidant in vitro and anti-tumor activity in vivo. J. Taiwan Institute of Chemical Engineers, 45(4): 1126-1132.

https://doi.org/10.1016/j.jtice.2013.12.004

Wang P.R., Chen D.F., Jiang D.H., Dong X.M., Chen P.P., and Lin Y.X., 2014b. Alkali extraction and in vitro antioxidant activity of monascus mycelium polysaccharides. J. Food Sci. Technol., 51(7): 1251-1259. https://doi.org/10.1007/s13197-012-0618-y

Yaich H., Garna H., Besbes S., Paquot M., Blecker C., and Attia H., 2013. Effect of extraction conditions on the yield and purity of ulvan extracted from Ulva lactuca. Food Hydrocolloids, 31(2): 375-382. https://doi.org/10.1016/j.foodhyd.2012.11.013

Yuan Y., Liu Y., Liu M.D., Chen Q., Jiao Y.Y., Liu Y., and Meng Z.L., 2017. Optimization extraction and bioactivities of polysaccharide from wild Russula griseocarnosa. Saudi Pharmaceutical J., 25(4): 523-530. https://doi.org/10.1016/j.jsps.2017.04.018

Zeng H.L., Zhang Y., Lin S., Jian Y.Y., Miao S., and Zheng B.D., 2015. Ultrasonic-microwave synergistic extraction (UMSE) and molecular weight distribution of polysaccharides from Fortunella margarita (Lour.) swingle. Separation and Purification Technol., 144: 97-106. https://doi.org/10.1016/j.seppur.2015.02.015

Zhang X.H., Liu L.N., and Lin C.W., 2014. Isolation, structural characterization and antioxidant activity of a neutral polysaccharide from Sisal waste. Food Hydrocolloids, 39: 10-18. https://doi.org/10.1016/j.foodhyd.2013.12.012

Zhao B.T., Zhang J., Guo X., and Wang J.L., 2013. Microwaveassisted extraction, chemical characterization of polysaccharides from Lilium davidii var. unicolor salisb and its antioxidant activities evaluation. Food Hydrocolloids, 31(2): 346-356. https://doi.org/10.1016/j.foodhyd.2012.11.021

Zhu A.S., Xu M.Q., and Zhao J.Z., 2017. Alkali extraction of polysaccharides from proso millet and antioxidant activity. Scientific Study Res. Chemistry Chemical Eng., Biotechnol., Food Industry, 18(4): 353-365.

Zhu A.S., Ye J.N., and Yan F.N., 2014. Optimization of extraction technology of polysaccharide from foxtail millet using response surface methodology. Chemical Industry Chemical Eng. Quarterly, 20(4): 579-585. https://doi.org/10.2298/ciceq130926040z 